Published in final edited form as:

Appetite. 2016 February 01; 97: 43-48. doi:10.1016/j.appet.2015.11.015.

\title{
The impact of sugar sweetened beverage intake on hunger and satiety in minority adolescents
}

\author{
Grace E. Shearrer ${ }^{1}$, Gillian O’Reilly², Britini Belcher, PhD, MPH ${ }^{3}$, Michael Daniels, ScD ${ }^{4}$, \\ Michael Goran, $\mathbf{P h D}^{5}$, Donna Spruijt-Metz, MFA, PhD $^{2}$, and Jaimie N. Davis, RD, PhD $^{1}$ \\ ${ }^{1}$ Department of Nutrition, University of Texas, Austin TX \\ ${ }^{2}$ Center for Economic and Social Research, University of Southern California \\ ${ }^{3}$ Risk Factor Monitoring and Methods Branch, Applied Research Program, National Cancer \\ Institute, Bethesda, MD \\ ${ }^{4}$ Department of Statistics and computation, University of Texas, Austin TX \\ ${ }^{5}$ Institute for Prevention Research, Department of Preventive Medicine, Keck School of Medicine, \\ University of Southern California, Los Angeles, CA
}

\section{Introduction}

African American and Hispanic adolescents are disproportionately at risk for obesity and metabolic disease (Taveras, Gillman, Kleinman, Rich-Edwards, \& Rifas-Shiman, 2013), with 39\% and 38\% being obese, respectively, compared with 31\% of Caucasian adolescents in the United States (Ogden, Carroll, Kit, \& Flegal, 2014). Additionally, adolescence is a time of increasing autonomy when youth begin to make independent dietary choices, and is therefore an ideal time to improve dietary habits in a high risk population (Bassett, Chapman, \& Beagan, 2008).

The increased prevalence of obesity in adolescent minority populations in the United States can be attributed to a multitude of factors. Two modifiable factors are the high intake of added sugars and the low intake of dietary fiber. A major contributor to added sugar in the diet of adolescents is sugar-sweetened beverages (SSB) such as carbonated sodas, sports drinks, and fruit drinks (Wang, Bleich, \& Gortmaker, 2008). African American and Hispanic youth consume on average more calories from SSB than their Caucasian peers (Wang et al., 2008). Increased SSB intake in adolescents was associated with higher systolic blood pressure, a risk factor for hypertension and cardiovascular disease (Nguyen, Choi, Lustig, \&

Correspondence author: Jaimie N. Davis, T. S. Painter Hall (PAI), The University of Texas at Austin, Department of Nutritional Sciences, 103 West $24^{\text {th }}$ Street, A2703, T.S. Painter Hall, Room 3.24, Austin, TX 78712, Telephone: 512-495-4705, Fax: (512) 475-5844, jaimie.davis@austin.utexas.edu.

The authors of this paper report no conflicts of interest. DSM, MIG, and JND were responsible for research design and conducted the experiment. GES and MJD analyzed the data and preformed statistical analysis. GES, JND, DSM, and GAO were the primary writers. GES, JND, DSM, GAO, MJD, and MIG provided edits for the paper. JND, DSM, and GES have primary responsibility for the content.

Publisher's Disclaimer: This is a PDF file of an unedited manuscript that has been accepted for publication. As a service to our customers we are providing this early version of the manuscript. The manuscript will undergo copyediting, typesetting, and review of the resulting proof before it is published in its final citable form. Please note that during the production process errors may be discovered which could affect the content, and all legal disclaimers that apply to the journal pertain. 
Hsu, 2009). Additionally, SSB intake has been associated with increased body weight in adolescents (Beck, Tschann, Butte, Penilla, \& Greenspan, 2013; Berkey, Rockett, Field, Gillman, \& Colditz, 2004; Ebbeling et al., 2006), with a dose responsive relationship between SSB intake and obesity risk in adolescents who consume four or more eight ounce servings per week (Martin-Calvo et al., 2014). Longitudinal data has shown that a single serving of SSB per day at age 15 years increased body mass index (BMI) and waist circumference over six years (Zheng et al., 2014).

Adolescents have been found to consume more fructose than any other age group over the last 30 years, and it has been suggested this in large part is due to use of high fructose corn syrup (HFCS) (Marriott, Cole, \& Lee, 2009). The principal sweetener in SSB is HFCS, which is comprised of nearly $50 \%$ more fructose than glucose (Walker, Dumke, \& Goran, 2014). Total dietary fructose has been shown to be positively related to increased visceral adiposity, increased blood pressure, and HOMA-IR in a large sample of adolescents (Pollock et al., 2012). An experiment comparing glucose, HFCS, sucrose, and sucralose found that food intake after a HFCS or sucrose drink led to higher energy intake at a subsequent ad libitum meal (Van Engelen et al., 2014).

Not only are adolescents more likely to consume fructose, but also adolescents are less likely to consume high fiber foods compared to other age groups. Adolescents consume on average 14 grams of fiber per day, substantially below the recommended 25 to 30 grams per day (Storey \& Anderson, 2014). Increasing satiety post meal is a desirable means of controlling and reducing weight. Satiety can be qualitatively measured via visual analogue scales and predicted via metabolic hormones such as peptide tyrosine tyrosine (PYY) and ghrelin (de Graaf, Blom, Smeets, Stafleu, \& Hendriks, 2004). Increased dietary fiber is an attractive means to increase post meal satiety as it is easily substituted in the diet and has been associated with weight loss (Flores, Maldonado, \& Durán, 2012). However current research is inconclusive regarding the effectiveness of fiber to improve satiety (Clark \& Slavin, 2013; Schroeder, Gallaher, Arndt, \& Marquart, 2009). Preliminary research examining the difference between the effect of high sugar versus high fiber meals on satiety measures has shown mixed results (Pasman, Blokdijk, Bertina, Hopman, \& Hendriks, 2003; Spruijt-Metz et al., 2009).

Previous research has focused on the satiating action of acute intake of either fiber or SSB (Chang et al., 2012; Soenen \& Westerterp-Plantenga, 2007; Van Engelen et al., 2014b; A J Wanders et al., 2011; Anne J Wanders et al., 2013). Research has shown acute satiety after a sugar pre-load (Anderson \& Woodend, 2003), however the effect of prolonged sugar consumption is, to date, understudied. An acute administration of a sugary beverage was associated with increased short term appetite in boys 9 to 14 years (Van Engelen et al., 2014a). Additionally, Cassady and colleagues has suggested lower satiety after a caloric liquid compared to an isocaloric solid, possibly due to a decreased gastric distention in the liquid as well as an aberrant endocrine response (Cassady, Considine, \& Mattes, 2012). Aberrant endocrine response is a hallmark of homeostatic break down over time, such as leptin resistance and ghrelin suppression in obesity (Kalra, 2001; Tschöp et al., 2001). These acute studies do not take into account the effect of habitual, free-living, intake of fiber and SSB. Given the mixed results of high sugar versus high fiber intake on satiety and the lack of 
research in minority youth, this study sought to compare the effects of free-living SSB intake and fiber intake on ghrelin and PYY levels during an acute fiber and sugar test meal challenge, and perceived hunger and fullness after the meal challenge during an ad libitum meal. Along these lines, we hypothesized that free-living high SSB consumers compared to low SSB consumers would have lower ghrelin and PYY regardless of the test meal and higher hunger and lower fullness during the ad libitum meals. We also hypothesized that free-living low fiber consumers compared to high fiber consumers would exhibit lower serum ghrelin and PYY regardless of the test meal type and be more hungry and less full during the ad libitum meals.

\section{Subjects and Methods}

Data comes from the FAME crossover feeding trial at the University of Southern California (USC). Conclusions based on the main outcomes and a detailed methodology can be found elsewhere (O'Reilly et al., 2015). This study was conducted at the USC Health Sciences campus in Los Angeles, California from 2008 to 2011. Subjects were recruited from hospitals, clinics, churches, schools, and community center around the Los Angeles area between 2007-2010. Hispanic and African American youth, ages 14 to 17 years, with a BMI above the $85^{\text {th }}$ percentile for age were recruited into the study. Subjects were excluded if they exhibited evidence of diabetes, were currently in a weight loss program, or used medications that influenced insulin or body composition. Informed written parental consent and participant assent was acquired before all testing procedures. The Institutional Review Board of USC approved all study procedures.

\section{Design}

Baseline measures-An initial, separate, baseline visit gathered demographic data and a licensed pediatric medical care provider collected body composition data and performed a physical exam. After the baseline visit, subjects were called for three multiple pass 24-hour dietary recalls by trained interviewers using the Nutrient Data System for Research (NDS-R 2010, University of Minnesota, Minneapolis, MN). All diet recalls were performed within one month of the first testing visit.

Testing: The testing visits were each nine hours long. The order in which subjects received either a high sugar and low fiber breakfast and lunch or a low sugar high fiber breakfast and lunch was randomly assigned. All participants completed both meals. Details pertaining to the meal type can be found here (O'Reilly et al., 2015). Subjects arrived at the USC health sciences center at 7:00am, where they completed anthropometrics, blood pressure testing, and questionnaires. The first blood draw was at 8:00 am. The breakfast was served directly after the initial blood draw and the lunch was served at noon. Subjects were given 15 minutes to finish the meals. The final blood draw occurred at 1:00 pm. From 1:00 pm to 4:00 pm the subjects were allowed access to an ad libitum meal tray and were instructed that they could eat as much or as little as they desired. A one-way mirror separated subjects and researchers so that the subject could not see the researchers. The subject also had access to a variety of games (Wii Fit, Dance Dance Revolution), movies, television, books, a craft 
corner and treadmill for the entire study period. After a two to four week washout period, subjects returned for the second identical testing visit but with the alternate test meal.

\section{Appetite/Satiety measurement}

A Registered Nurse placed a saline lock intravenous catheter in the antecubital vein of the non-dominant arm. Blood was drawn every 30 minutes during the test meal phase of the visit (the first five hours). Although blood was drawn on all subjects, funding only allowed a random subset of subjects to be assayed for PYY and ghrelin. Every 30 minutes for the entire lab visit the subject was given a $100 \mathrm{~mm}$-visual analogue scale (VAS) to rate how hungry he or she felt, as well as a VAS to rate how full he or she felt. All blood collected was centrifuged and processed within one hour of collection and was stored at -70 until analysis. Active ghrelin concentrations were analyzed via enzyme-linked immunosorbent assay (ELISA) (Millipore, Darmstadt, Germany). Total PYY was analyzed by radioimmunoassay (RIA) (Millipore, Darmstadt, Germany).

Subjects were classified for high volume SSB consumers based on the dietary recall data: low SSB consumers ( $\leq 1$ servings per day), medium SSB consumers ( $>1-\leq 2$ servings per day), and high SSB consumers ( $>2$ servings per day). SSB consumer groups were used evaluate the change in dependent variables in a dose dependent manner, as well as to minimize reporter bias. Drinks considered SSB were as follows: sweetened soft drinks, sweetened fruit drinks, sweetened tea, sweetened coffee, sweetened coffee substitutes, and sweetened water. A serving was defined as 8 fluid ounces. Fiber was divided into the following quartile categories for test meal analysis based on dietary recall data: very low ( $\leq$ 3.6 grams per day), low (between 3.6 and 9.9 grams per day), medium (between 9.9 and 13.5 per day), high volume consumers ( $>13.5$ grams per day). For the ad libitum meal analysis fiber was divided into the following quartile categories based on dietary recall data: very low fiber intake ( $\leq 5.8$ grams per day), low fiber intake ( $>5.8-\leq 9.8$ grams per day), medium fiber intake ( $>9.8-\leq 15.5$ grams per day), high fiber intake ( $>15$ grams per day). Because of the difference in sample sizes between the test meals phase and the ad libitum meal phase two different quartiles were calculated for each phase. Hunger and fullness ratings, which ranged from 0 to 100 were transformed using a logit function to better satisfy the normality assumption in the models. Of the appetite variables, hunger and fullness were analyzed from 300 to 480 minutes after 8:00 am (during the ad libitum meal period), while ghrelin and PYY were analyzed from 0 to 300 minutes, starting at 8:00am (during the test meal phase). Differences in hunger, fullness, ghrelin, and PYY concentration were evaluated initially between the two test meal types. No differences between the high sugar and low fiber and the low sugar and high fiber meal were found. Therefore, the data from both test meals was used in the evaluation of hunger, fullness, ghrelin, and PYY concentration.

\section{Statistical Analysis}

All analyses were performed with R version 3.1.2 (R Foundation for Statistical Computing, Vienna, Austria). Initially, the high sugar and low fiber breakfast and lunch were compared to the low sugar high fiber test meals using a repeated measure t-test. The LME function from the nlme 3.1-119 package was used to fit linear mixed effects models with a random intercept and slope to assess the effect of meal type, SSB group, fiber group, and time on the 
two appetite variables (hunger, fullness). In the model, the fixed effect of time was modeled using a spline with three degrees of freedom with the basis matrix for natural cubic splines (ns) function from the splines 3.1.2 package in R. The baseline models included the dependent variable of interest (hunger, fullness, ghrelin or PYY concentration) and only the spline for time as the independent variable. The following other independent variables were added stepwise: SSB category, fiber category, ethnicity, overweight or obese status, sex, and energy intake (calories per day). Multiplicative interaction terms were added to the models according to individual independent variable significance also in a stepwise fashion. Loglikelihood tests were used to compare the relative fit of nested models after each stepwise categorical variable addition with the lrtest function from the latest 0.99-33 package. Statistical significance was set at $\mathrm{p} \leq 0.05$ and beta value $(\beta)$ refers to the regression coefficient.

\section{Results}

\section{Participant Characteristics}

A total of 93 subjects were randomized into the initial meal study. Seven withdrew after randomization for a total of 87 participants that completed both meals. Of the 87 who completed both study visits, 47 participants had two or more diet recalls within one month of each other and test visit data. A subsample of 18 subjects, concentrations for which assayed blood samples were available, was analyzed for ghrelin and PYY. There were no significant differences in sex, caloric intake, overweight or obese status between the subsample which was assayed for PYY and ghrelin and the overall sample, although the blood subsamples were made up predominately of Hispanic youth (only 7.7\% African American) and all African Americans subjects were medium SSB volume consumers. Table 1 summarizes the demographics of the entire sample (the ad libitum meal phase) and the subset (the test meal phase). Neither SSB nor fiber intake were significantly different by day of recall. None of the variables of interest were different between high sugar and low fiber nor high fiber low sugar test meals.

\section{Test meal phase}

The effect of SSB was significant in the ghrelin model ( $\mathrm{p}=0.03$ ). In particular, the low SSB consumers exhibited higher ghrelin concentrations compared to the high SSB consumers over time during the test meal $(\beta=-1.86, \mathrm{CI}=(-2.81,-0.92), \mathrm{p}<0.01)$. This difference in SSB consumption is visualized in Figure 1 as the difference in the shift of the SSB group curves. There were not significant differences between fiber groups and serum ghrelin concentrations over time during the test meal.

There were no significant differences between SSB groups and serum PYY over time during the test meal. Nor were there significant differences between fiber groups and serum PYY concentrations over time during the test meal. 


\section{Ad libitum meal phase}

There were no significant differences between SSB groups and hunger ratings during the ad libitum meal phase. Nor were there significant differences between fiber groups and hunger ratings during the ad libitum meal phase.

SSB categories significantly improved the predictive ability of the fullness model compared to baseline ( $\mathrm{p}=0.03$ ). The low SSB group was more full compared to the high SSB group during the ad libitum meal phase $(\beta=-0.49, \mathrm{CI}=(-0.89,-0.08), \mathrm{p}=0.02)$. This difference in SSB consumption is visualized in Figure 2 as the difference in the shift of the SSB group curves. There were no significant differences between fiber groups and fullness ratings during the ad libitum meal.

\section{Discussion}

This is the first study to show that free-living SSB intake influences feelings of fullness and ghrelin response during a crossover meal design. Although initially there were no differences between the two meals given during the crossover meal trial, free living SSB intake revealed differences overall. High SSB consumers were on average more full during the ad libitum meal phase compared to low SSB consumers. Interestingly, SSB consumption did not influence hunger over the ad libitum meal phase. Low SSB consumers exhibited higher ghrelin concentrations during the test meals phase compared to high SSB consumers. However, SSB group did not influence PYY. Dietary fiber was not significantly related to hunger, fullness, ghrelin or PYY.

Previous research has focused on acute intake of SSB or dietary fiber on appetite (Chang et al., 2012; Soenen \& Westerterp-Plantenga, 2007; Van Engelen et al., 2014a; A J Wanders et al., 2011; Anne J Wanders et al., 2013). Studies focusing on immediate satiety after a sugar preload have found an increase in satiety and caloric compensation at ad libitum meals, which aligns with the well accepted glucostatic theory (Birch, McPhee, \& Sullivan, 1989; Canty \& Chan, 1991). The glucostatic theory postulates that the increase in blood glucose and blood insulin acts as a satiety signal in the short term and allows for caloric compensation. This current study suggests an alternative hypothesis for free-living SSB consumption, suggesting high SSB intake is associated with lower feelings of satiety. Preceding work has suggested that SSB increases caloric intake, greater than that achieved through SSB intake alone, and therefore SSB may suppress satiety or increase appetite (Vartanian, Schwartz, \& Brownell, 2007). SSB intake has also been associated with weight gain, however when caloric intake was included in the models the relationship was attenuated (Berkey et al., 2004; Schulze et al., 2004). Since this current study controls for caloric intake and weight status, the findings further suggest that the relationship between SSB and fullness are independent of caloric intake and BMI in this sample.

Furthermore, this study's examination of metabolic hormones further reveals a possible mechanism. The glucostatic theory, mentioned above, breaks down over time in overweight and obese subjects resulting in hyperinsulinemia and eventually insulin resistance. Emerging research shows a similar pattern with leptin resistance (Kalra, 2001) and ghrelin suppression in obesity (Tschöp et al., 2001). The HELENA study showed that SSB consumption was 
positively related to homeostasis model assessment-insulin resistance index (HOMA-IR) in European adolescents (Kondaki et al., 2013). Insulin, and in particular HOMA-IR, has been shown to be negatively associated with serum ghrelin (Marzullo et al., 2004). This study found suppressed ghrelin in the highest SSB consumer group, independent of weight status. The association between HOMA-IR and SSB intake and these results showing suppressed ghrelin for high SSB consumption suggests a possible mechanism for long term alterations in fullness. High SSB consumption appears to suppress ghrelin resulting in decreased fullness ratings in the high SSB group. Further research is needed to explore the relationship between satiety, SSB, and other endocrine signals such as insulin and leptin, which have been shown to influence ghrelin.

There are several limitations of the current study. The relatively small sample size ( $\mathrm{n}=47)$ is a limitation, particularly the small sample $(\mathrm{n}=18)$ with PYY and ghrelin data; thus lack of statistical significance could be due to low power. In addition, this study included more Hispanic children than African American children; therefore, these results may not be applicable for the general African American population. Additionally, this study was in overweight and obese Hispanic and African American adolescents, and the findings may not be generalizable to other ethnicities and/or lean individuals. In addition, since this study is a crossover meal test study and cross-sectional in nature, causality of SSB intake on satiety status and ghrelin concentration cannot be assessed. Finally, it should be noted that only two or three dietary recalls were performed, which could impact the reliability of the measure. Ideally, four to five dietary recalls would provide a more robust measurement of habitual dietary intake (Ma et al., 2009). Furthermore, the 24-hour recall method is subject to reporter bias, and may under estimate actual intake.

In conclusion, high free-living SSB intake appears to play a role in moderating fullness in a meal test. These findings highlight that future research should consider the effects of long term free-living diet, particularly SSB consumption. Additionally, high intake of SSB appears to lower ghrelin response. Future interventions should focus on reducing SSB consumption.

\section{Acknowledgments}

\section{Source of support:}

This work was supported by the National Institute for Minority Health and Health Disparities (NIMHD) as part of the USC Minority Health Center of Excellence (NCHMD P60 MD002254) and the National Institutes of Cancer (NCI), NCI Centers for Transdisciplinary Research on Energetics and Cancer (TREC, U54 CA 116848) as part of the USC Center for Transdisciplinary Research on Energetics and Cancer.

\section{Abbreviations \\ SSB Sugar Sweetened Beverage \\ HSLF High sugar low fiber \\ LSHF Low sugar high fiber \\ HFCS High fructose corn syrup}




$\begin{array}{ll}\text { PYY } & \text { peptide tyrosine tyrosine } \\ \text { USC } & \text { University of Southern California } \\ \text { BMI } & \text { Body mass index } \\ \text { VAS } & \text { Visual Analog Scale } \\ \text { ELISA } & \text { Enzyme-linked immunosorbent assay } \\ \text { RIA } & \text { Radioimmunoassay } \\ \text { LME } & \text { Linear mixed effects }\end{array}$

\section{References}

Anderson GH, Woodend D. Effect of glycemic carbohydrates on short-term satiety and food intake. Nutrition Reviews. 2003; 61(5 Pt 2):S17-26. Retrieved from http://www.ncbi.nlm.nih.gov/pubmed/ 12828188. [PubMed: 12828188]

Bassett R, Chapman GE, Beagan BL. Autonomy and control: the co-construction of adolescent food choice. Appetite. 2008; 50(2-3):325-32. DOI: 10.1016/j.appet.2007.08.009 [PubMed: 17936413]

Beck AL, Tschann J, Butte NF, Penilla C, Greenspan LC. Association of beverage consumption with obesity in Mexican American children. Public Health Nutr. 2013; :1-7. DOI: 10.1017/ S1368980012005514

Berkey CS, Rockett HRH, Field AE, Gillman MW, Colditz GA. Sugar-added beverages and adolescent weight change. Obesity Research. 2004; 12(5):778-88. DOI: 10.1038/oby.2004.94 [PubMed: 15166298]

Birch LL, McPhee L, Sullivan S. Children's food intake following drinks sweetened with sucrose or aspartame: time course effects. Physiology \& Behavior. 1989; 45(2):387-95. Retrieved from http:// www.ncbi.nlm.nih.gov/pubmed/2756027. [PubMed: 2756027]

Canty DJ, Chan MM. Effects of consumption of caloric vs noncaloric sweet drinks on indices of hunger and food consumption in normal adults. The American Journal of Clinical Nutrition. 1991; 53(5):1159-64. Retrieved from http://www.ncbi.nlm.nih.gov/pubmed/2021127. [PubMed: 2021127]

Cassady BA, Considine RV, Mattes RD. Beverage consumption, appetite, and energy intake: what did you expect? The American Journal of Clinical Nutrition. 2012; 95(3):587-93. DOI: 10.3945/ajcn. 111.025437 [PubMed: 22258267]

Chang KT, Lampe JW, Schwarz Y, Breymeyer KL, Noar KA, Song X, Neuhouser ML. Low glycemic load experimental diet more satiating than high glycemic load diet. Nutrition and Cancer. 2012; 64(5):666-73. DOI: 10.1080/01635581.2012.676143 [PubMed: 22564018]

Clark MJ, Slavin JL. The effect of fiber on satiety and food intake: a systematic review. Journal of the American College of Nutrition. 2013; 32(3):200-11. DOI: 10.1080/07315724.2013.791194 [PubMed: 23885994]

de Graaf C, Blom WA, Smeets PA, Stafleu A, Hendriks HF. Biomarkers of satiation and satiety. Am J Clin Nutr. 2004; 79(6):946-961. Retrieved from http://ajcn.nutrition.org/content/79/6/946.full. [PubMed: 15159223]

Ebbeling CB, Feldman HA, Osganian SK, Chomitz VR, Ellenbogen SJ, Ludwig DS. Effects of decreasing sugar-sweetened beverage consumption on body weight in adolescents: a randomized, controlled pilot study. Pediatrics. 2006; 117(3):673-80. DOI: 10.1542/peds.2005-0983 [PubMed: 16510646]

Flores G, Maldonado J, Durán P. Making tortillas without lard: Latino parents' perspectives on healthy eating, physical activity, and weight-management strategies for overweight Latino children. Journal of the Academy of Nutrition and Dietetics. 2012; 112(1):81-9. DOI: 10.1016/j.jada. 2011.08.041 [PubMed: 22717179] 
Kalra SP. Circumventing leptin resistance for weight control. Proceedings of the National Academy of Sciences of the United States of America. 2001; 98(8):4279-81. DOI: 10.1073/pnas.091101498 [PubMed: 11296275]

Kondaki K, Grammatikaki E, Jiménez-Pavón D, De Henauw S, González-Gross M, Sjöstrom M, Manios Y. Daily sugar-sweetened beverage consumption and insulin resistance in European adolescents: the HELENA (Healthy Lifestyle in Europe by Nutrition in Adolescence) Study. Public Health Nutrition. 2013; 16(3):479-86. DOI: 10.1017/S1368980012002613 [PubMed: 23009737]

Ma Y, Olendzki BC, Pagoto SL, Hurley TG, Magner RP, Ockene IS, Hébert JR. Number of 24-hour diet recalls needed to estimate energy intake. Annals of Epidemiology. 2009; 19(8):553-9. DOI: 10.1016/j.annepidem.2009.04.010 [PubMed: 19576535]

Marriott BP, Cole N, Lee E. National estimates of dietary fructose intake increased from 1977 to 2004 in the United States. The Journal of Nutrition. 2009; 139(6):1228S-1235S. DOI: 10.3945/jn. 108.098277 [PubMed: 19403716]

Martin-Calvo N, Martínez-González MA, Bes-Rastrollo M, Gea A, Ochoa MC, Marti A. Sugarsweetened carbonated beverage consumption and childhood/adolescent obesity: a case-control study. Public Health Nutrition. 2014; 17(10):2185-93. DOI: 10.1017/S136898001300356X [PubMed: 24485091]

Marzullo P, Verti B, Savia G, Walker GE, Guzzaloni G, Tagliaferri M, Liuzzi A. The relationship between active ghrelin levels and human obesity involves alterations in resting energy expenditure. The Journal of Clinical Endocrinology and Metabolism. 2004; 89(2):936-9. DOI: 10.1210/jc. 2003-031328 [PubMed: 14764817]

Nguyen S, Choi HK, Lustig RH, Hsu C. Sugar-sweetened beverages, serum uric acid, and blood pressure in adolescents. The Journal of Pediatrics. 2009; 154(6):807-13. DOI: 10.1016/j.jpeds. 2009.01.015 [PubMed: 19375714]

O'Reilly GA, Belcher BR, Davis JN, Martinez LT, Huh J, Antunez-Castillo L, Spruijt-Metz D. Effects of high sugar and high fiber meals on physical activity behaviors in Latino and African American adolescents. Obesity (Silver Spring, Md). 2015 In Press.

Ogden CL, Carroll MD, Kit BK, Flegal KM. Prevalence of childhood and adult obesity in the United States, 2011-2012. JAMA : The Journal of the American Medical Association. 2014; 311(8):80614. DOI: 10.1001/jama.2014.732 [PubMed: 24570244]

Pasman WJ, Blokdijk VM, Bertina FM, Hopman WPM, Hendriks HFJ. Effect of two breakfasts, different in carbohydrate composition, on hunger and satiety and mood in healthy men. International Journal of Obesity and Related Metabolic Disorders : Journal of the International Association for the Study of Obesity. 2003; 27(6):663-8. DOI: 10.1038/sj.ijo.0802284

Pollock NK, Bundy V, Kanto W, Davis CL, Bernard PJ, Zhu H, Dong Y. Greater fructose consumption is associated with cardiometabolic risk markers and visceral adiposity in adolescents. The Journal of Nutrition. 2012; 142(2):251-7. DOI: 10.3945/jn.111.150219 [PubMed: 22190023]

Schroeder N, Gallaher DD, Arndt EA, Marquart L. Influence of whole grain barley, whole grain wheat, and refined rice-based foods on short-term satiety and energy intake. Appetite. 2009; 53(3):363-9. DOI: 10.1016/j.appet.2009.07.019 [PubMed: 19643157]

Schulze MB, Manson JE, Ludwig DS, Colditz GA, Stampfer MJ, Willett WC, Hu FB. Sugarsweetened beverages, weight gain, and incidence of type 2 diabetes in young and middle-aged women. JAMA. 2004; 292(8):927-34. DOI: 10.1001/jama.292.8.927 [PubMed: 15328324]

Soenen S, Westerterp-Plantenga MS. No differences in satiety or energy intake after high-fructose corn syrup, sucrose, or milk preloads. The American Journal of Clinical Nutrition. 2007; 86(6):158694. Retrieved from http://ajcn.nutrition.org/content/86/6/1586.abstract. [PubMed: 18065574]

Spruijt-Metz D, Belcher B, Anderson D, Lane CJ, Chou CP, Salter-Venzon D, Weigensberg MJ. A high-sugar/low-fiber meal compared with a low-sugar/high-fiber meal leads to higher leptin and physical activity levels in overweight Latina females. Journal of the American Dietetic Association. 2009; 109(6):1058-63. DOI: 10.1016/j.jada.2009.03.013 [PubMed: 19465188]

Storey M, Anderson P. Income and Race/Ethnicity Influence Dietary Fiber Intake and Vegetable Consumption. Nutrition Research. 2014; doi: 10.1016/j.nutres.2014.08.016 
Taveras EM, Gillman MW, Kleinman KP, Rich-Edwards JW, Rifas-Shiman SL. Reducing racial/ethnic disparities in childhood obesity: the role of early life risk factors. JAMA Pediatrics. 2013; 167(8): 731-8. DOI: 10.1001/jamapediatrics.2013.85 [PubMed: 23733179]

Tschöp M, Weyer C, Tataranni PA, Devanarayan V, Ravussin E, Heiman ML. Circulating ghrelin levels are decreased in human obesity. Diabetes. 2001; 50(4):707-9. Retrieved from http:// www.ncbi.nlm.nih.gov/pubmed/11289032. [PubMed: 11289032]

Van Engelen M, Khodabandeh S, Akhavan T, Agarwal J, Gladanac B, Bellissimo N. Effect of sugars in solutions on subjective appetite and short-term food intake in 9- to 14-year-old normal weight boys. European Journal of Clinical Nutrition. 2014a; 68(7):773-7. DOI: 10.1038/ejen.2014.33 [PubMed: 24667751]

Van Engelen M, Khodabandeh S, Akhavan T, Agarwal J, Gladanac B, Bellissimo N. Effect of sugars in solutions on subjective appetite and short-term food intake in 9- to 14-year-old normal weight boys. European Journal of Clinical Nutrition. 2014b; 68(7):773-7. DOI: 10.1038/ejen.2014.33 [PubMed: 24667751]

Vartanian LR, Schwartz MB, Brownell KD. Effects of soft drink consumption on nutrition and health: a systematic review and meta-analysis. American Journal of Public Health. 2007; 97(4):667-75. DOI: 10.2105/AJPH.2005.083782 [PubMed: 17329656]

Walker RW, Dumke KA, Goran MI. Fructose content in popular beverages made with and without high-fructose corn syrup. Nutrition (Burbank, Los Angeles County, Calif). 2014; 30(7-8):928-35. DOI: $10.1016 /$ j.nut.2014.04.003

Wanders AJ, Jonathan MC, van den Borne JJGC, Mars M, Schols HA, Feskens EJM, de Graaf C. The effects of bulking, viscous and gel-forming dietary fibres on satiation. The British Journal of Nutrition. 2013; 109(7):1330-7. DOI: 10.1017/S0007114512003145 [PubMed: 22850326]

Wanders AJ, van den Borne JJGC, de Graaf C, Hulshof T, Jonathan MC, Kristensen M, Feskens EJM. Effects of dietary fibre on subjective appetite, energy intake and body weight: a systematic review of randomized controlled trials. Obesity Reviews : An Official Journal of the International Association for the Study of Obesity. 2011; 12(9):724-39. DOI: 10.1111/j.1467-789X. 2011.00895.x [PubMed: 21676152]

Wang YC, Bleich SN, Gortmaker SL. Increasing caloric contribution from sugar-sweetened beverages and $100 \%$ fruit juices among US children and adolescents, 1988-2004. Pediatrics. 2008; 121(6):e1604-14. DOI: 10.1542/peds.2007-2834 [PubMed: 18519465]

Zheng M, Rangan A, Olsen NJ, Bo Andersen L, Wedderkopp N, Kristensen P, Heitmann BL. Sugarsweetened beverages consumption in relation to changes in body fatness over 6 and 12 years among 9-year-old children: the European Youth Heart Study. European Journal of Clinical Nutrition. 2014; 68(1):77-83. DOI: 10.1038/ejen.2013.243 [PubMed: 24281311] 


\section{Highlights}

- High sugar sweetened beverage intake appears to be related to a decrease in fullness at an ad libitum meal.

- Ghrelin appears to be depressed in high sugar sweetened beverage consumers compared to low sugar sweetened beverage consumers.

- Sugar sweetened beverage intake should be taken into account when looking at satiety measures after standardized test meals. 
Active serum ghrelin concentration over the test meal phase

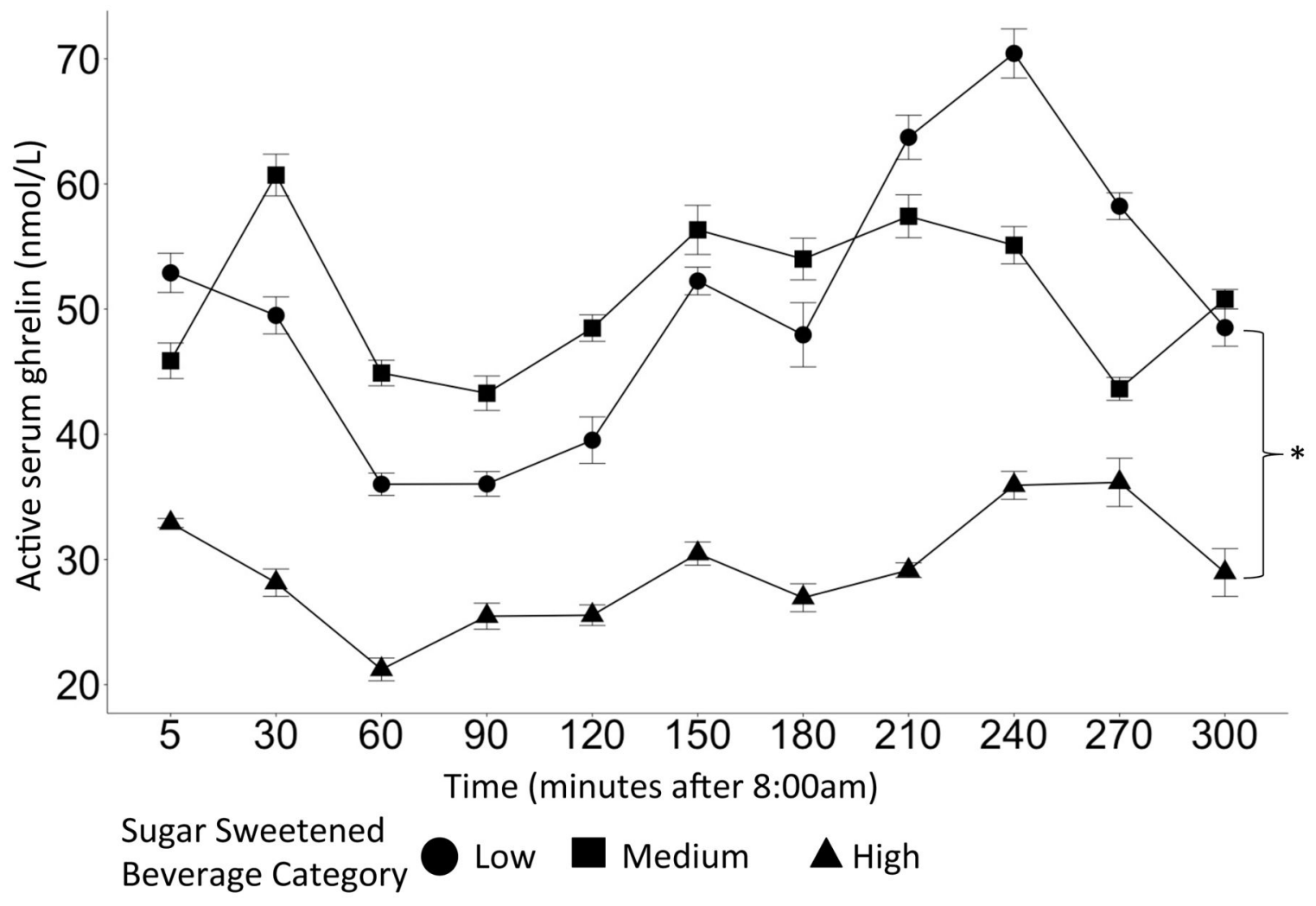

Figure 1.

Serum ghrelin concentration over time during the test meals phase. This sample contained 18 subjects. High SSB consumer group exhibited lower active ghrelin than the low SSB group $(\mathrm{p}<0.01)$. Error bars represent the confidence interval. 


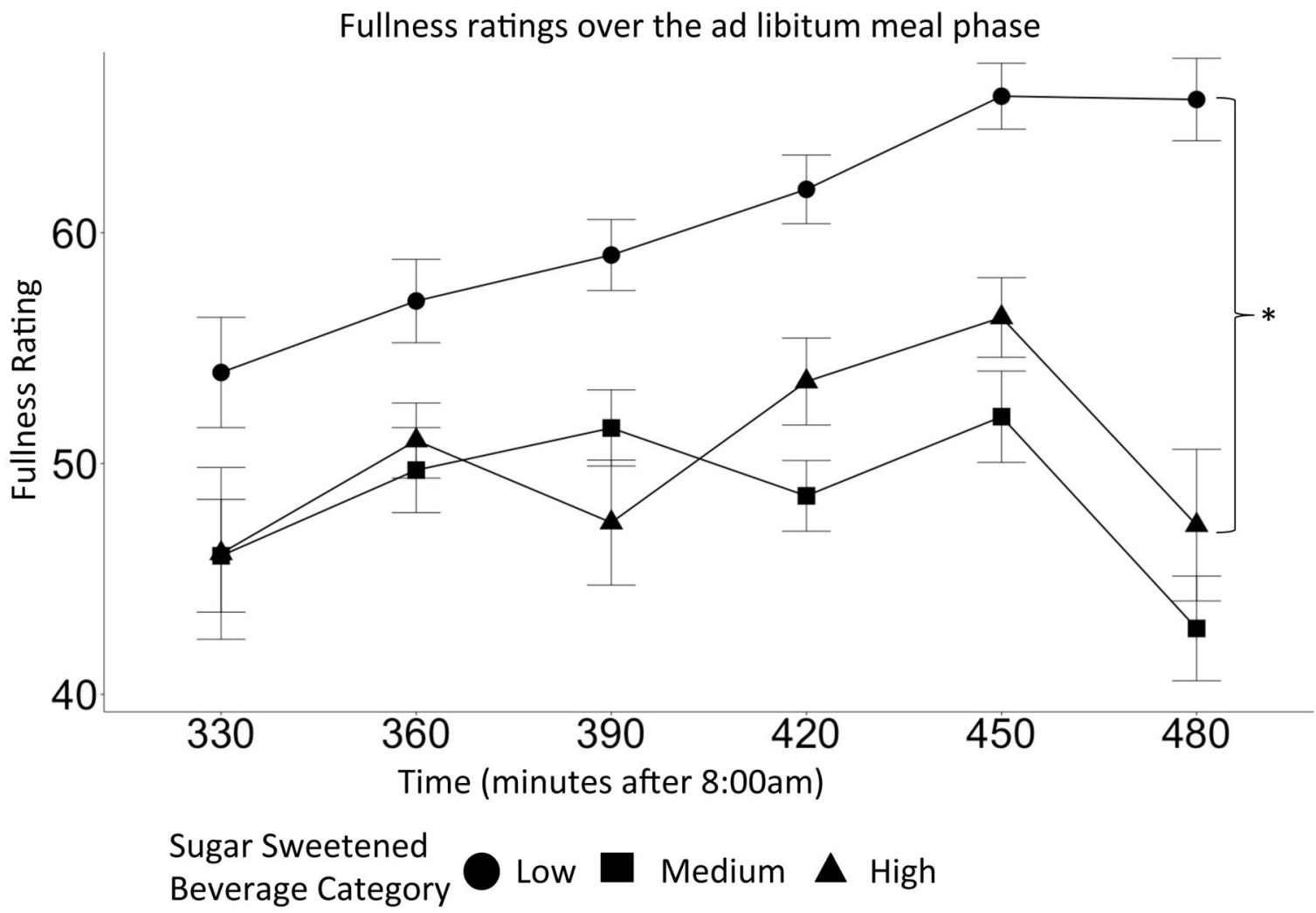

Figure 2.

Fullness ratings as indicated by visual analogue scale over the ad libitum meal between fiber intake groups. The low SSB consumers, compared to the high SSB consumers, where more full ( $\mathrm{p}=0.02)$. Error bars represent the confidence interval. 


\section{을 \\ 골}

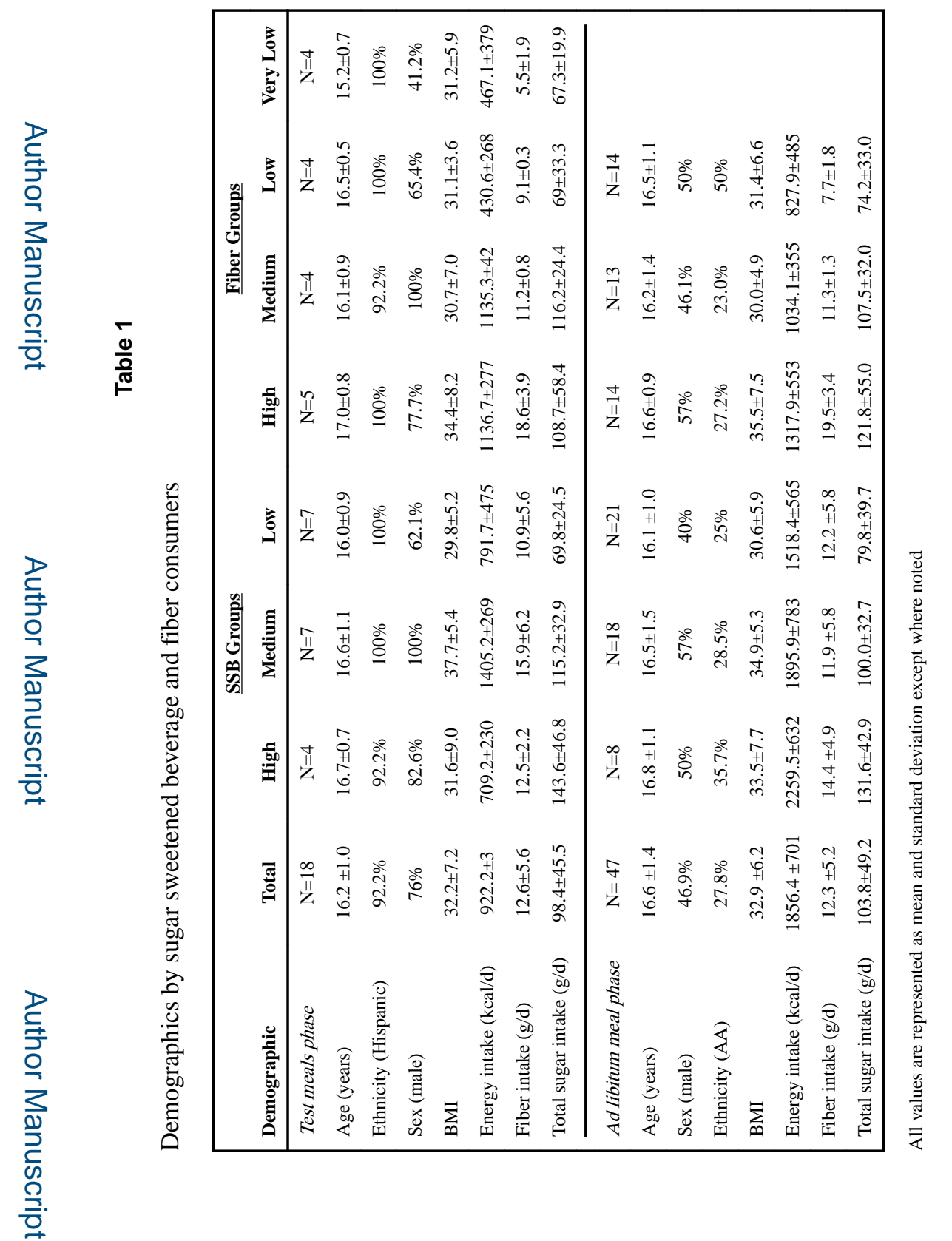

Appetite. Author manuscript; available in PMC 2017 February 01. 